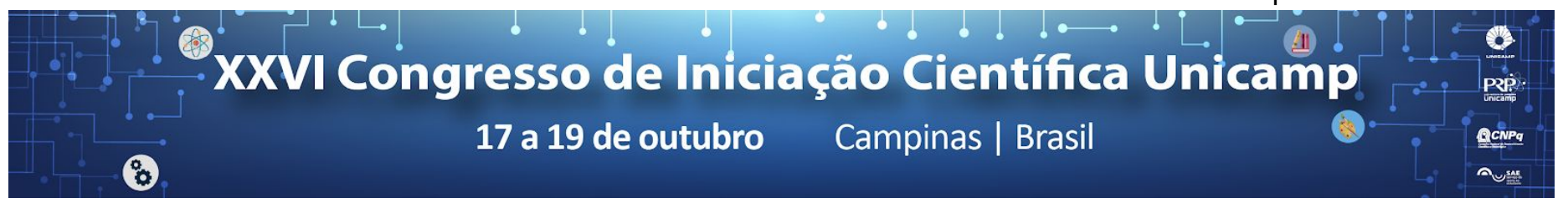

\title{
Importância e funcionalidade dos biomateriais desenvolvidos em impressoras 3D
}

\author{
Rebeca O. Silva*, Júlia A. Nogueira, Larissa Maria L. Quintela, Heloísa G. Argentin, Paulo I. Neto, Janaina A. \\ Dernowsek, Jorge V. L. da Silva.
}

\begin{abstract}
Resumo
Hoje com o avanço tecnológico estamos conhecendo um mundo totalmente novo voltado para pesquisas medicinais com a engenharia tecidual, direcionada para formação de tecidos in silico, in vitro ou in vivo. Uma das abordagens da engenharia de tecidos implica a produção de scaffolds, suportes necessário para adesão, proliferação e diferenciação mantendo as funções biológicas de cada célula. Os biomateriais têm um papel muito importante no desenvolvimento dessas células e cada um influencia de forma diferenciada para cada tipo de célula em crescimento.
\end{abstract}

\section{Palavras-chave:}

Biomaterial, scaffolds, biofabricação.

\section{Introdução}

A engenharia tecidual auxiliada com tecnologias tridimensionais e a tecnologia da informação, tem como objetivo produzir substitutos para tecidos biológicos defeituosos, deformados ou produtos que ajudem a acelerar a regeneração e reparo desses tecidos (Andrea Dernowsek et al., 2017). O estudo de biomateriais auxilia no desenvolvimento do scaffold, estrutura tridimensional, que pode ser biodegradável, que serve como suporte e superfície de adesão para a proliferação e crescimento da célula (Hutmacher, 2001). Cada biomaterial atua de forma específica no crescimento de cada tecido em particular.

\section{Resultados e Discussão}

Os scaffolds são fabricados pela impressora Fab@CTI por um processo extrusão. A Fab@CTI tem um medidor de temperatura e um tubo pelo qual o material é aquecido até fundir, formando os filamentos moldados pelo bico da Fab.(Maurmann et al., 2015). Os scaffolds são feitos primeiramente por um programa FABatHOME que contêm os parâmetros/configurações necessárias para a sua construção e futuramente podem ser usados na cultura de células na engenharia tecidual.

A policaprolactona ( $P C L$ ) é considerado um biomaterial, é biocompatível, biodegradável, bioabsorvíveis e bioinerte. (Barbanti et al.,2005). O seu ponto de fusão é 59 a $64^{\circ} \mathrm{C}$ e para fazer os scaffolds foi mantido a temperatura em $80^{\circ} \mathrm{C}$ deixando maleável e facilitando a extrusão.

Estudo comprova que polímeros sintéticos como o poli(ع-caprolactona) (PCL) permite a produção de um suporte com maior estabilidade mecânica e poli(ácido lático-co-ácido glicólico) (PLGA) um polímero excelente em propriedades de adesão celular, proliferação e degradação. ( Maurmann et al., 2015).

Os scaffolds não foram testados para proliferação celular, pois o foco deste trabalho é o processamento do material biocompatível (PCL), utilizado em uma impressora 3D, observando os parâmetros de número de filamentos, número de camadas, diâmetro, altura e temperatura. Para complementar as metas da pesquisa, serão realizados estudos sobre o comportamento da proliferação celular e a utilização de outros tipos de materiais e/ou biomateriais.

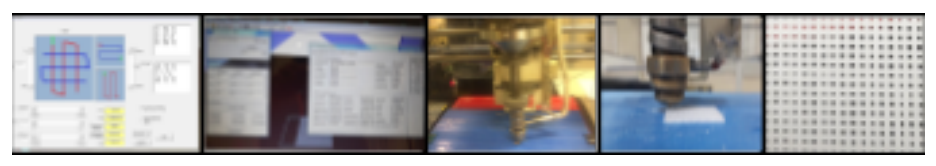

Figura 1. Etapas importantes na produção de Scaffolds pela Fab@CTI, Material (PCL).

\section{Conclusões}

Os biomateriais são essenciais para o desenvolvimento da célula estando ele in vivo ou in vitro e a falta de um tipo de biomaterial ou a presença dele, pode prejudicar a proliferação celular. Observe-se que a Fab@CTI é importante na produção de scaffolds, pois foram impressos com a geometria esperada, utilizando biomaterial $(P C L)$ e obtendo resultado satisfatório.

\section{Agradecimentos}

Agradeço imensamente ao CNPQ, PIBIC e aos meus colegas de trabalho NT3D/CTI Renato Archer.

ANDRÉA DERNOWSEK, Janaina. et al. The role of information technology in the future of 3D biofabrication. Journal of 3D printing in medicine, v. 1, n. 1, p. 63-74, 2017.

HUTMACHER, Dietmar W. Scaffold design and fabrication technologies for engineering tissues-state of the art and future perspectives. Journal of Biomaterials Science, Polymer Edition, v. 12, n. 1, p. 107-124, 2001.

MAURMANN, Natasha et al. MATRIZES 3D DE PCL COBERTAS POR NANOFIBRAS DE PLGA PARA A ENGENHARIA DE TECIDOS. In: $13^{\circ}$ Congresso Brasileiro de Polímeros, 2015, Natal, RN, Anais do $\mathbf{1 3}^{\circ}$ Congresso Brasileiro de Polímeros, 2015. Disponível em: $<$ http://cbpol.com.br/anais/2015/pdfs/plenary/AMDJ.pdf $>$ Acesso em : 12 jul. 2018.

BARBANTI, Samuel H. et al. Polímeros bioreabsorvíveis na engenharia de tecidos. Polímeros, 2005 